\title{
High-Dose Lovastatin for Acute Ischemic Stroke: Results of the Phase I Dose Escalation Neuroprotection with Statin Therapy for Acute Recovery Trial (NeuSTART)
}

\author{
Mitchell S.V. Elkind ${ }^{\mathrm{a}}$ Ralph L. Sacco ${ }^{\mathrm{h}}$ Robert B. MacArthur ${ }^{\mathrm{b}}$ Ellinor Peerschke \\ Greg Neils ${ }^{f}$ Howard Andrews $^{f}$ Joshua Stillman ${ }^{c}$ Tania Corporan ${ }^{a}$ \\ Dana Leiferg Rui Liu ${ }^{d}$ Ken Cheung ${ }^{d}$ \\ ${ }^{a}$ Department of Neurology, College of Physicians and Surgeons, ${ }^{b}$ Research Pharmacy, ${ }^{c}$ Department of Emergency \\ Medicine, College of Physicians and Surgeons, and d Department of Biostatistics, Mailman School of Public Health, \\ Columbia University, ${ }^{e}$ Center for Clinical Laboratories, Mount Sinai School of Medicine, ${ }^{\mathrm{f}}$ New York State Psychiatric \\ Institute, and ${ }^{9}$ Department of Neurology, Weill Cornell Medical College, New York, N.Y., and ${ }^{\text {h}}$ Department of \\ Neurology, Miller School of Medicine, University of Miami, Miami, Fla., USA
}

\section{Key Words}

Acute ischemic stroke $\cdot$ Statins

\begin{abstract}
Background: Hydroxymethylglutaryl coenzyme A reductase inhibitors ('statins') reduce the neuronal injury in dosedependent fashion in rodent stroke models. We sought to determine whether lovastatin at doses above those currently approved can be administered safely within $24 \mathrm{~h}$ after an acute ischemic stroke. Methods: We conducted a phase 1B dose-finding study using an adaptive design novel to stroke trials, the continual reassessment method, to find the highest tolerated dose of lovastatin. Planned doses were 1, 3, 6, 8 and $10 \mathrm{mg} / \mathrm{kg} /$ day for 3 days. The primary safety outcomes were myotoxicity and hepatotoxicity. The model was calibrated to select a dose causing 7-13\% toxicity. Results: We enrolled 33 patients ( 16 men/17 women, age range $23-82$ years). Three patients were treated at $1 \mathrm{mg} / \mathrm{kg}, 10$ at $3 \mathrm{mg} / \mathrm{kg}$, 12 at $6 \mathrm{mg} / \mathrm{kg}$, and 8 at $8 \mathrm{mg} / \mathrm{kg}$. Thirty of the 33 patients (90.9\%) completed at least 11 of 12 doses. Two patients at the $6-\mathrm{mg} / \mathrm{kg}$ dose level experienced transient mild elevations in
\end{abstract}

transaminases without clinical sequelae. After an initial dose reduction, the dose was re-escalated to $8 \mathrm{mg} / \mathrm{kg}$, and no further patients reached safety outcomes. No clinical liver disease, myopathy, or creatine phosphokinase elevations occurred. The final model-based toxicity at $8 \mathrm{mg} / \mathrm{kg}$ was $13 \%$; no patient was treated at $10 \mathrm{mg} / \mathrm{kg}$. Conclusions: Lovastatin at doses above those currently approved by the Food and Drug Administration is feasible for 3 days after an acute ischemic stroke and the maximum tolerated dose is estimated to be $8 \mathrm{mg} / \mathrm{kg} /$ day. Further randomized studies are warranted to confirm its safety and to demonstrate its efficacy in improving functional outcomes after stroke.

Copyright $\odot 2009$ S. Karger AG, Basel

\section{Introduction}

Hydroxymethylglutaryl coenzyme A reductase inhibitors, or 'statins', prevent myocardial infarction, stroke, and other vascular events $[1,2]$. Their benefit may be partly independent of their effects on lowering cholesterol [3-5]. Experimental and clinical evidence sug-

\section{KARGER}

๑ 2009 S. Karger AG, Basel

Fax +4161306 1234 E-Mail karger@karger.ch www.karger.com www.karger.com/ced
Mitchell S.V. Elkind, MD

Neurological Institute

710 West 168th Street, Box 182

New York, NY 10032 (USA)

Tel. +1 212305 1710, Fax +1 212305 1658,E-Mail mse13@columbia.edu 
gest that by reducing downstream products of the mevalonate pathway other than cholesterol, statins can have beneficial effects on endothelial function, coronary and cerebral blood flow, inflammation, and hemostasis $[4,5]$. More recently, experimental studies have demonstrated that several statins can reduce neuronal injury and infarct size in rodent models of acute ischemic stroke [613]. In these animal models, statins have been given both before the experimental stroke and as an acute treatment early $(3 \mathrm{~h})$ after the stroke. The mechanism of this neuroprotection is also independent of the effect on cholesterol, and appears primarily related to improved endothelial function, increased cerebral blood flow, and reduced inflammation, rather than to a direct neuronal cytoprotective benefit. Furthermore, the greatest neuroprotective effect in these studies was seen at the highest doses, with a dose-response effect. There is also evidence that statins may have pro-restorative effects on neuronal recovery after stroke when used up to $24 \mathrm{~h}$ later, including angiogenesis, synaptogenesis, and neurogenesis [14].

Observational studies and preliminary clinical trials in humans have provided some support for a benefit of statins administered at traditional doses in acute ischemic stroke. Patients already taking statins at the time of stroke have better functional outcomes and reduced mortality compared to patients not taking statins, as shown in many studies [15-19]. One pilot randomized trial of simvastatin $40 \mathrm{mg}$ daily in acute ischemic stroke patients reported a benefit in neurological exam scores as early as 3 days after treatment, though consistent benefits in functional outcomes were not maintained at 90 days [20]. Another randomized study found that cessation of standard-dose statins in patients already on them led to worse outcomes [21]. Other observational studies and small trials have failed to confirm a benefit and have suggested a potential for increased risk $[22,23]$. It is of note that all trials thus far have focused on standard doses of statins, although animal models have suggested that there is a dose-response effect on neuroprotection. It is plausible, therefore, that statin doses higher than currently approved for long-term cholesterol reduction may be of greater benefit in acute stroke than traditional doses.

Early-phase trials in cancer patients have provided evidence that statins at doses above the approved level are well-tolerated for short periods of time in humans. Lovastatin, in particular, has been tested in humans at doses similar to and higher than those that have been shown to be neuroprotective in rodent models [24-27]. Because there may be important differences between cancer and
Table 1. Starting dose escalation plan

\begin{tabular}{lllll}
\hline $\begin{array}{l}\text { Phase 1B } \\
\text { cohort } \\
\begin{array}{l}\text { No. } \\
\text { size }\end{array}\end{array}$ & $\begin{array}{l}\text { Cohort } \\
\mathrm{n}\end{array}$ & $\begin{array}{l}\text { Lovastatin dose } \\
\text { every 6h for 72 h } \\
\mathrm{mg} / \mathrm{kg} / \text { day }\end{array}$ & $\begin{array}{l}\text { Maximum dose, } \\
\text { based on dose } \\
\text { calculated for } \\
\text { weight of 100 kg } \\
\mathrm{mg}\end{array}$ & $\begin{array}{l}\text { Dose } \\
\text { days 3-30 } \\
\mathrm{mg} / \mathrm{day}\end{array}$ \\
\hline 1 & 3 & 1 & 100 & 20 \\
2 & 3 & 3 & 300 & 20 \\
3 & 6 & 6 & 600 & 20 \\
4 & 9 & 8 & 800 & 20 \\
5 & 12 & 10 & 1,000 & 20 \\
Total & 33 & & & \\
\hline
\end{tabular}

These dose levels applied before any dose-limiting toxicity was observed. The Data and Safety Monitoring Committee met to discuss continuation to the next cohort after every 3 patients were enrolled. Dose (de-)escalation was conducted according to the time-to-event CRM once a dose-limiting toxicity was observed.

stroke patients in patient characteristics, including age and comorbid illness, and disease pathophysiology, including a potential high risk of hemorrhagic complications in stroke patients, proof of safety in stroke patients is required. Despite their role in vascular prophylaxis, no translational studies have been performed to test the safety of statins at doses higher than currently approved when administered as early therapy in stroke patients. The investigator-initiated Neuroprotection with Statin Therapy for Acute Recovery Trial (NeuSTART) drug development program was started to provide data on the safety, pharmacokinetics, and pilot efficacy of this approach. This paper describes the main results of a phase 1B dose-escalation and dose-finding study designed to test the hypothesis that short-term statin therapy, at doses that are maximally effective in animal studies of neuroprotection, is feasible and safe in patients with acute ischemic stroke. We further provide pharmacokinetic data and provide an example of use of an adaptive statistical design, the time-to-event continual reassessment method (CRM) [28, 29], which has until now been novel to acute stroke research.

\section{Methods}

The rationale, methods, and protocol for this study have been described in detail in a previous publication [30]. Briefly, NeuSTART was a 2-center phase $1 \mathrm{~B}$ dose-escalation and dose-finding study in which ischemic stroke patients were treated within $24 \mathrm{~h}$ of symptom onset at escalating dosage levels of short-term 
Table 2. Inclusion and exclusion criteria

\section{Inclusion criteria}

1 Patient's age is $\geq 18$

2 Patient satisfies criteria for ischemic stroke: acute focal neurological deficit of likely ischemic vascular origin

3 Patient or legally authorized representative has provided written informed consent prior to study entry

4 Patient can receive first treatment dose within 0-24 h of stroke onset; for patients found with stroke on awakening, it will be assumed that the stroke occurred the last time they were known to be normal

5 Patient has pretreatment brain CT scan compatible with ischemic stroke that excludes hemorrhagic and nonvascular etiologies of symptoms

6 Patients taking statins at time of stroke may be included

\section{Exclusion criteria}

1 Brain imaging study shows lesion other than ischemic stroke that could explain patient's symptoms (intracranial or subarachnoid hemorrhage, arteriovenous malformation, aneurysm, multiple sclerosis, tumor, abscess or other); asymptomatic meningiomas are allowed

2 Mild stroke, defined as NIHSS $<2$

3 Patient has received or is expected to receive intravenous rt-PA within $3 \mathrm{~h}$ or intra-arterial rt-PA within $6 \mathrm{~h}$ of stroke onset, according to our institutional standard of care

4 Patient has received intravenous rt-PA after $3 \mathrm{~h}$ or intraarterial rt-PA after $6 \mathrm{~h}$ after stroke onset

5 Patient is comatose, regardless of etiology ( $>4$ points on the first 3 items of the NIHSS)

6 Patient has history of intolerance or allergic reaction to any statins (myotoxicity, hepatic dysfunction, rash or other)

7 Patient has used drugs within past 30 days that utilize the cytochrome CYP3A pathway (cyclosporine, itraconazole, ketoconazole, erythromycin, azithromycin, clarithromycin or nefazodone)

8 Patient has used drugs within past 30 days that increase risk of myotoxicity with statins (gemfibrozil, other fibrates, niacin, amiodarone or verapamil)

9 Baseline major electrolyte disturbances (sodium $<125$ or $>150$, potassium $<3.0$ or $>5.5$ )
10 Recent major trauma ( $<3$ months)

11 Hypothermia (body temperature $<96^{\circ} \mathrm{F}$ )

12 Baseline hypoxia (defined as oxygen saturation $<92 \%$ on room air)

13 Patient has history of likely or proven systemic viral infection within 30 days

14 Patient has known HIV infection or used protease inhibitors

15 Endocarditis likely as cause of stroke

16 Mitochondrial disorder likely as cause of stroke

17 Pregnancy or lactation

18 Patient has history of rhabdomyolysis, myopathy or other severe muscle disease

19 Patient has history of hepatitis, decompensated liver disease (ascites, bleeding varices or encephalopathy) or liver failure

20 Liver function tests (ALT, AST) $\geq 2 \times$ upper limit of normal

21 Unstable cardiovascular (including uncontrolled hypertension), pulmonary, gastrointestinal, hepatic or musculoskeletal disease

22 Patient has evidence of congestive heart failure or has history of end-stage cardiovascular disease (e.g. CHF NYHA class III or IV or unstable angina)

23 Abnormal ECG showing: hemodynamically significant arrhythmia or frequent PVCs ( $>5 / \mathrm{min}$; controlled atrial arrhythmia will not be an exclusion criterion); evidence of acute myocardial infarction; Mobitz II 2nd-degree AV block or 3rd-degree AV block; ventricular tachycardia or ventricular fibrillation

24 Significant renal insufficiency, indicated by serum creatinine $>2.0 \mathrm{mg} / \mathrm{dl}$

25 Hypoglycemia (glucose $<60 \mathrm{mg} / \mathrm{dl}$ ) or diabetic ketoacidosis unresponsive to therapy

26 Any of these hematologic abnormalities: $\mathrm{Hb}<10 \mathrm{~g} / \mathrm{dl}$; WBC $<3.0 \times 10^{3} / \mathrm{mm}^{3}$; platelet count $<50,000 / \mathrm{mm}^{3}$

27 Patient has received investigational drug within 30 days

28 Patient has severe behavioral or social problems that may interfere with the conduct of clinical study procedures

29 Patient is unlikely, in the investigator's opinion, to complete the study and return for follow-up visits for any reason

NIHSS = National Institutes of Health Stroke Scale; rt-PA = recombinant tissue-type plasminogen activator; CHF = congestive heart failure; NYHA = New York Heart Association; PVC = premature ventricular contraction; $\mathrm{AV}=$ atrioventricular; $\mathrm{Hb}=$ hemoglobin; $\mathrm{WBC}=$ white blood count.

high-dose lovastatin (the initial dose plan was $1,3,6,8$, or $10 \mathrm{mg} /$ $\mathrm{kg}$ /day for 3 days; table 1). Lovastatin was chosen because of the preliminary data available from safety trials in cancer patients and because of Food and Drug Administration concerns about safety at higher doses with certain other statins. Patients with acute ischemic stroke who could be treated within $24 \mathrm{~h}$ of symptom onset were eligible. A time window of $24 \mathrm{~h}$ was chosen be- cause the primary goal of the study was to assess safety. Inclusion and exclusion criteria are listed in table 2 [30]. Patients who were treated with intravenous tissue plasminogen activators were excluded from the trial because of Food and Drug Administration concerns that a high-dose statin therapy might either interfere with the efficacy of the tissue plasminogen activators or lead to an increased risk of hemorrhage due to effects on the platelet func- 
tion. The study was approved by the institutional review boards of the 2 participating hospitals, and all patients provided informed consent.

The patients were administered the total daily dose in 4 divided doses, to be consistent with cancer trials that demonstrated safety at high doses in that patient population [24-26]. The study drug was administered orally to most patients and via a nasogastric tube to dysphagic patients. After the initial 3 days, all patients received lovastatin $20 \mathrm{mg}$ daily for 27 days (table 1), unless they had experienced toxicity, to avoid any statin withdrawal effects. They received an actual dose within $6 \%$ of the target calculated dose on a milligram per kilogram basis. The maximum daily dose for any individual patient was based on a maximum weight of $100 \mathrm{~kg}$. Other medications that increase the risk of myopathy were prohibited [30]. Patients already taking statins were enrolled as long as the patient and treating physician were willing to discontinue the current statin in favor of the study medication.

Significant muscle or hepatic toxicity was chosen as the primary endpoint for the study based on well-established understanding of the likely toxicity expected with statin agents gained from multiple prior clinical trials in patients with cardiovascular disease as well as from the results of smaller early-phase studies in cancer patients [24-26]. The primary safety outcome was the development of clinical or laboratory evidence of major hepatic or muscle toxicity. The definition of the primary safety outcome, in keeping with other statin trials [31,32], was defined as either: (1) liver toxicity: liver function test [alanine aminotransferase (ALT) and/or aspartate aminotransferase (AST)] levels increase at any time point $>3$ times the upper limit of normal (ULN), development of jaundice, otherwise unexplained coagulopathy, or other clinical evidence of hepatitis or liver failure; or (2) muscle toxicity: increase in creatine phosphokinase (CK) at any time point $>10$ times the ULN, or clinical evidence of muscle pain or weakness not related to the stroke and associated with $\mathrm{CK}>5$ times the ULN.

Safety laboratory tests, including liver function tests and CK, were measured at baseline (on day 0 prior to drug administration) and on days 1, 2, 3, 5, 7 and 30. A muscle and liver clinical assessment of pain, strength, jaundice, and bleeding was also completed at baseline and on days 1, 2, 3, 5, 7 and 30. Pharmacokinetic analyses were also made, and inflammatory biomarkers [high-sensitivity C-reactive protein (hsCRP), interleukin-6 (IL-6), tumor necrosis factor- $\alpha$ (TNF), and TNF receptor 1 (TNFR1)] as well as lipid levels were assessed at these intervals to provide another measure of activity. Vital signs were measured every $4 \mathrm{~h}$ during the first $72 \mathrm{~h}$ postdose, and on days 7 and 30 . Expected and unexpected adverse events, the use of concomitant medication, and compliance with study procedures were assessed throughout the study.

\section{Statistical Analysis and Sample Size Calculations}

Details of the statistical methodology used in this trial have been published previously [30]. Briefly, the objective was to determine the maximal tolerated dose (MTD) in this patient population. We defined the MTD as the dose associated with a $10 \%$ rate of occurrence of the primary safety endpoint or the dose-limiting toxicity within the 30 -day treatment period. The study design tolerates $10 \%$ toxicity in stroke patients in order to be able to treat patients at a higher and thus potentially efficacious dose.
Patients were scheduled to be enrolled in groups of size 3 . The first 3 patients received dose level 1 ( $1 \mathrm{mg} / \mathrm{kg} /$ day $)$. Once a primary safety event was observed, the time-to-event CRM [28, 29, 33] was used to determine dose escalation, and each individual patient was given a dose based on the updated dose-toxicity model at the time the patient was enrolled into the trial. The local Data and Safety Monitoring Committee made the final determination whether an event was related to the study therapy. Under the time-to-event CRM paradigm, when a patient was eligible for enrollment, the toxicity probability was estimated for each dose, based on safety information accrued up to that time and the prior expectation of toxicity; the estimation was based on the posterior mean of an empiric dose-toxicity model (see fig. 2, filled circle curve) [34]. The new patient was then assigned to the current estimate of MTD. The dose toxicity model was calibrated such that the time-to-event CRM would converge to assign a dose that caused $7-13 \%$ toxicity, within 3\% of our target [35]. After enrollment finished, we calculated the final estimate of the probability of developing a safety event for each dose, using both the Bayesian posterior calculation and the maximum likelihood estimation. The $95 \%$ CIs of the toxicity probabilities were also calculated based on the maximum likelihood estimates [36].

We planned to accrue 33 evaluable patients using the timeto-event CRM with an empiric dose-toxicity model [34]. This design would select the correct MTD with probabilities over $50 \%$ in our simulated scenarios. More importantly, given our primary focus on safety in this study, the probability of choosing a dose with a $25 \%$ or higher likelihood of toxicity was no more than $18 \%$. Generally, a sample size of 33 patients ensures that estimates of any binary variable will have a 95\% CI of width $\leq 0.34$ and will enable us to detect any unexpected toxicity that occurs at a $5 \%$ rate (in a non-dose-dependent fashion) with a 0.82 probability.

Because we considered the possibility that there could be doserelated increases in laboratory tests short of reaching a primary safety outcome, we also performed exploratory analyses of liver, muscle, other laboratory tests, and vital signs during the first $72 \mathrm{~h}$ among the dose levels. Linear mixed effects models were used to assess the dose effects and adjust for the time trend on the laboratory measurements. Nonparametric Jonckheere-Terpstra tests were also used to assess dose effects on liver and muscle tests at each posttreatment time point. Marker levels were log-transformed as needed to stabilize the variance. The changes from baseline on a log scale in marker levels of hsCRP, IL-6, TNF, and TNFR1 were analyzed using the linear mixed effects models with dose and time as fixed covariates. Time trends were explored graphically by plotting all these outcomes against the times of measurement for each patient. Secondary safety outcomes and adverse events were tabulated and summarized by the observed rates and $95 \%$ CIs.

\section{Source of Funding}

This trial was conducted as part of an investigator-initiated program project funded by the National Institutes of Health and the National Institute of Neurological Disorders and Stroke, which focused on the therapy of acute stroke (the New York-Columbia Collaborative Specialized Program of Translational Research in Acute Stroke - SPOTRIAS). Two centers participated, the initiating Columbia University Medical Center and a second center at New York Hospital-Cornell. 


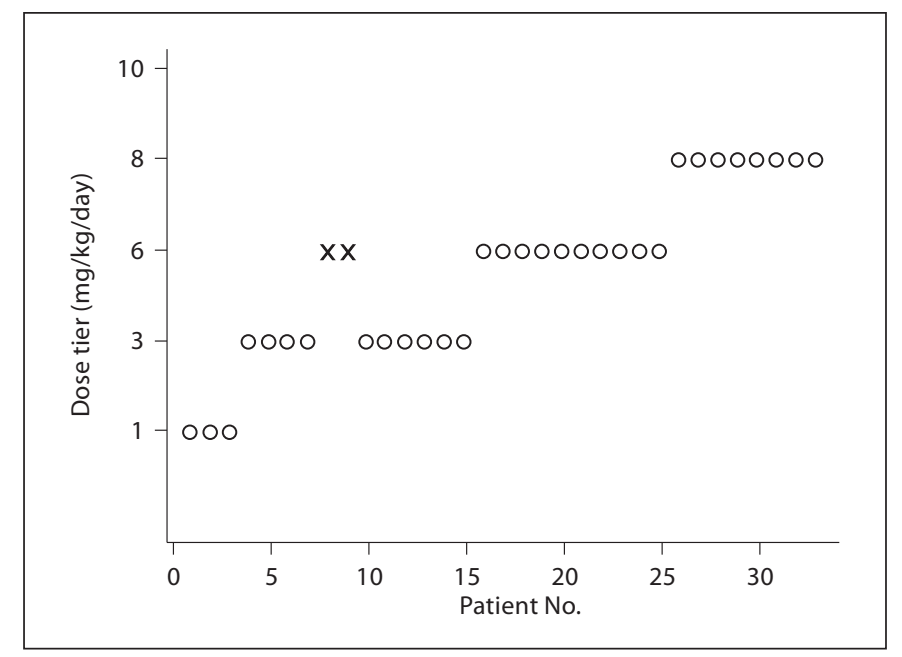

Fig. 1. Patient flow throughout the course of the trial. Patients are presented in chronological order from left to right. Open circles indicate patients treated without reaching a primary safety outcome. Crosses indicate patients who reached primary safety outcomes. Note that dose de-escalation occurred after 2 patients reached primary safety outcomes at the $6-\mathrm{mg} / \mathrm{kg}$ dose tier. The second patient in this pair was enrolled before the first patient was noted to reach a primary safety outcome.

\section{Results}

The patient characteristics are presented in table 3 . It is of note that $91 \%$ of the patients completed 11 of 12 of the 4 divided daily doses during days $1-3$ of the study. Figure 1 shows the course of patient flow, including the dose escalation, de-escalation, and re-escalation in the study. The figure illustrates that, after 2 toxic events occurred at the third dose level $(6 \mathrm{mg} / \mathrm{kg} /$ day), the dose was de-escalated to $3 \mathrm{mg} / \mathrm{kg} / \mathrm{day}$. Two patients were treated at the dose level of $6 \mathrm{mg} / \mathrm{kg}$ before dose de-escalation because they were enrolled at about the same time and the second event occurred before the first had been recognized. The dose was then re-escalated when the modelbased toxicity was again compatible with a toxicity of $7-$ $13 \%$. The study was stopped when the originally planned 33 patients were enrolled, and a maximum dose of $8 \mathrm{mg} /$ $\mathrm{kg}$ was given. No further toxic events occurred. The final model-based estimate of toxicity was 13\% (95\% CI 3$28 \%$ ) for a dose of $8 \mathrm{mg} / \mathrm{kg} /$ day (fig. 2).

Online suppl. fig. 1 (www.karger.com/doi/10.1159/000228709) shows the peak levels of the primary safety laboratory tests for each patient. Two patients exceeded the toxicity threshold ( 3 times the ULN) for either AST or ALT, but no patients exceeded 5 times the ULN for CK. The mixed

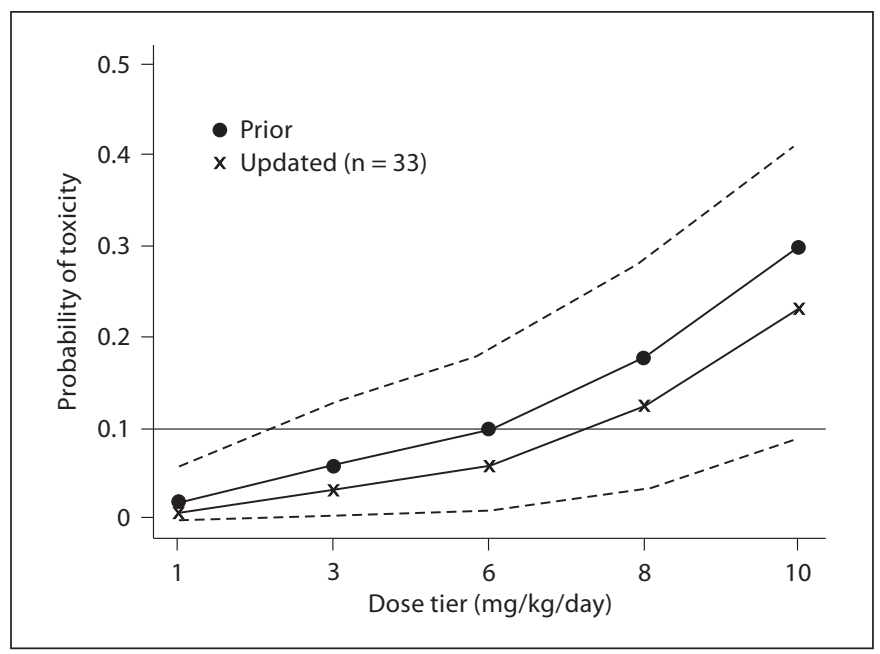

Fig. 2. Model-based probabilities of dose-limiting toxicity. Filled circles represent a priori assumptions about dose-limiting toxicity. Crosses represent the point estimates of the final probabilities calculated from the CRM model. Dashed lines represent the 95\% CI for the final probabilities.

Table 3. Summary of patient characteristics

\begin{tabular}{lc}
\hline Patient characteristics & Mean \pm SD, or $\mathrm{n}(\%)$ \\
\hline Total & 33 \\
Age, years & \\
$\quad$ Mean \pm SD & $62 \pm 15.0$ \\
$\quad$ Range & $23-82$ \\
Men & $16(48.4)$ \\
Race & $16(48.4)$ \\
Hispanic & $7(21.2)$ \\
Non-Hispanic white & $9(27.3)$ \\
Non-Hispanic black & $1(3.0)$ \\
Asian & 5 \\
NIH Stroke Score at baseline & $2-17$ \\
$\quad$ Median & $15.7 \pm 7.2$ \\
Range & $1.0-25.1$ \\
Time from symptom onset to treatment initiation, h \\
$\quad$ Mean \pm SD & $11(33.3)$ \\
Range & $15(45.5)$ \\
Stroke subtype & $4(12.1)$ \\
Cardioembolic & $3(9.1)$ \\
Lacunar & \\
Large vessel atherosclerotic & $30(90.9)$ \\
Other/cryptogenic & $32(97.0)$ \\
Treatment & \\
Completed $\geq 11$ of 12 doses & \\
Completed $\geq 9$ of 12 doses & \\
\hline
\end{tabular}

$\mathrm{NIH}=$ National Institutes of Health. 
effects models of the CK and aminotransferase levels provided evidence for modest dose effects ( $p=0.09$ for the $\mathrm{CK}$ and $\mathrm{p}=0.08$ for aminotransferase levels). JonckheereTerpstra tests confirmed a slight dose-related decline in CK on day $1(\mathrm{p}=0.042)$ and a dose-related subclinical elevation in AST on days 5 and $7(\mathrm{p}=0.026$ and 0.037 , respectively). All levels returned to normal no later than 30 days after.

There was a significant decrease in TNF- $\alpha$ receptor 1 (TNFR1) levels associated with dose increase; TNFR1 decreased by $1.6 \%(\mathrm{p}=0.051)$ per unit increase in the dose $(\mathrm{mg} / \mathrm{kg})$. There was no effect on CRP, IL-6, or TNF levels. Total cholesterol, low-density lipoprotein, and triglyceride levels decreased acutely after the stroke and then increased again over 30 days. High-density lipoprotein levels remained stable. There was no evidence of an effect of the dose level on the lipid or triglyceride levels. There was also a trend toward a decrease in systolic blood pressure measured at 4-hour intervals during the first $72 \mathrm{~h}(-2.0 \%$ per unit dose increase; $p=0.064)$, but no significant change in pulse or diastolic blood pressure.

Platelet aggregation studies, using high-dose ADP as a stimulant to test for additional effects beyond the expected antiaggregatory effects of aspirin therapy alone, demonstrated no significant dose-related effects on platelet aggregation. Additional studies using collagen and ristocetin similarly demonstrated no evidence of any dose-related decrease in platelet aggregation. Platelet secretion studies using ADP and collagen demonstrated a low secretion in almost all patients, consistent with the use of antiplatelet agents; 1 patient with normal secretion to ADP was on warfarin. There was no evidence of a doserelated decrease in antiplatelet efficacy.

The frequency of anticipated, prespecified secondary safety outcomes and the 95\% CIs are shown in table 4 . The most frequent events were neurological worsening and infections ( $\mathrm{n}=5$ patients for both). Three episodes of neurological worsening occurred at a dose of $3 \mathrm{mg} / \mathrm{kg} /$ day and 3 at a dose of $6 \mathrm{mg} / \mathrm{kg} /$ day; there were none at 1 or $8 \mathrm{mg} / \mathrm{kg} /$ day. Infections included 3 urinary tract infections, 1 cellulitis, and 1 pneumonia. One infection occurred at $1 \mathrm{mg} / \mathrm{kg} / \mathrm{day}, 3$ at $6 \mathrm{mg} / \mathrm{kg} /$ day, and 1 at $8 \mathrm{mg} /$ $\mathrm{kg} /$ day. There was no statistical evidence of any association of these outcomes with the dose level, but the number of participants was relatively small to permit exclusion of any such effect. There were no episodes of aspiration pneumonia, bladder or bowel incontinence, brain herniation, cough, deep venous thrombosis, or phlebitis. Four patients experienced a gastrointestinal upset, 3 within the first 7 days. In addition, 2 patients had to vom-
Table 4. Prespecified secondary safety outcomes

\begin{tabular}{|c|c|c|}
\hline Secondary safety outcomes & $\mathrm{n}$ & $\%(95 \% \mathrm{CI})$ \\
\hline Clinically significant hypotension ${ }^{1}$ & 2 & $6.1(0-14.2)$ \\
\hline Symptomatic hemorrhagic conversion ${ }^{2}$ & 1 & $3.0(0-8.9)$ \\
\hline Neurological worsening ${ }^{3}$ & 5 & $15.2(2.9-27.4)$ \\
\hline Progression of stroke & 1 & $3.0(0-8.9)$ \\
\hline Infections ${ }^{4}$ & 5 & $15.2(2.9-27.4)$ \\
\hline Depression & 2 & $6.1(0-14.2)$ \\
\hline Dysphagia & 2 & $6.1(0-14.2)$ \\
\hline Speech disorder & 3 & $9.1(0-18.9)$ \\
\hline
\end{tabular}

${ }^{1}$ Defined as development of new symptoms or signs (syncope, decreased mental status, new neurological deficit, decline in NIHSS $\geq 2$ points) attributed to a decline in systolic or diastolic blood pressure of $\geq 10 \mathrm{~mm} \mathrm{Hg}$. Other causes of these symptoms must have been excluded.

${ }^{2}$ Defined as a decline of $\geq 2$ points on the NIHSS and CT evidence of new hemorrhage.

${ }^{3}$ Defined as a decline of $\geq 2$ points on the NIHSS in the absence of any new hemorrhage on the CT scan.

${ }^{4}$ Defined as infections that require treatment with antibiotics, are life-threatening, result in additional disability or prolonged hospitalization (including - but not limited to - urinary tract infections, bacteremia, pneumonia, and cellulitis).

it within the first 7 days and 2 patients had diarrhea, 1 of them within the first 7 days. A total of 9 serious adverse events occurred in 7 patients (table 5). Three of these 9 events were considered possibly related to the study medication, but none were considered as definitely related.

Pharmacokinetic assays showed linear pharmacokinetics at these higher-than-approved doses of lovastatin, up to the maximum tested dose of $8 \mathrm{mg} / \mathrm{kg} /$ day. Blood levels of lovastatin (prodrug) and lovastatin acid (the primary active metabolite) were measured at single time points around expected peak and trough times near the first dose $(0,2 \mathrm{~h})$ and the last dose $(66,68 \mathrm{~h})$, as well as after the end of the dosing period $(120 \mathrm{~h})$. We compared the pharmacokinetic parameters of this study with published data using the same dosage form (immediate release) at standard doses (40 mg single dose) [37]. For lovastatin and lovastatin acid, all peak and trough values measured were within the 95\% CI around the expected values. For lovastatin acid, the values were consistently closer to projected values than the lovastatin values. The area under the concentration time curve was also consistent with published data, with no unusual values observed. For both analytes, there was no indication of accumulation or nonlinear metabolic rates over the studied dosage range. 
Table 5. Serious adverse events

\begin{tabular}{|c|c|c|c|c|c|}
\hline & Event diagnosis & $\begin{array}{l}\text { Dose } \\
\text { tier } \\
\mathrm{mg} / \mathrm{kg}\end{array}$ & Outcome & $\begin{array}{l}\text { Study drug } \\
\text { action }\end{array}$ & $\begin{array}{l}\text { Related to study } \\
\text { medication }\end{array}$ \\
\hline 67-year-old non-Hispanic man & recurrent stroke & 3 & resolved with sequelae & none & not related \\
\hline $\begin{array}{l}42 \text {-year-old non-Hispanic } \\
\text { white woman }\end{array}$ & TIA & 3 & resolved & none & not related \\
\hline Same patient & TIA & 3 & resolved & none & not related \\
\hline 77-year-old Hispanic woman & recurrent stroke & 3 & resolved with sequelae & none & not related \\
\hline 78-year-old Hispanic woman & atrial fibrillation & 3 & resolved & none & not related \\
\hline $\begin{array}{l}69 \text {-year-old } \\
\text { non-Hispanic woman }\end{array}$ & acute renal failure & 6 & resolved & $\begin{array}{l}\text { permanently } \\
\text { discontinued }\end{array}$ & possibly \\
\hline $\begin{array}{l}\text { 56-year-old } \\
\text { non-Hispanic woman }\end{array}$ & $\begin{array}{l}\text { extension of infarct } \\
\text { secondary to hypovolemia } \\
\text { and hypoperfusion }\end{array}$ & 6 & resolved & none & not related \\
\hline $\begin{array}{l}\text { 72-year-old } \\
\text { non-Hispanic man }\end{array}$ & $\begin{array}{l}\text { intermittent dysarthria, } \\
\text { bradycardia }\end{array}$ & 6 & resolved & none & possibly \\
\hline Same patient & urinary tract infection & 6 & resolved & none & possibly \\
\hline
\end{tabular}

TIA $=$ Transient ischemic attack.

\section{Discussion}

The presently described trial represents a potential new approach to the treatment of acute ischemic stroke, as well as a novel way of conducting a phase I trial evaluating safety and determining an optimal dose of a possible neuroprotectant drug. We found that higher doses of the generically available hydroxymethylglutaryl coenzyme A reductase inhibitor lovastatin than currently approved by the FDA are feasible and tolerated in patients with acute ischemic stroke presenting within $24 \mathrm{~h}$ of symptom onset. While there was some evidence of mild transient increases in liver function tests, as might be expected with statins, there was no evidence of clinically significant liver or muscle disease. Other adverse events also occurred in the study, as would be expected among a group of stroke patients, but there was no clear evidence of a pattern of increasing adverse events with increasing doses. We did, however, find evidence that the inflammatory marker TNFR1 may be decreased in a dose-dependent fashion and a suggestion that there might be a modest dose-related blood-pressure-lowering effect. The clinical implications of these changes are uncertain, however, and larger, randomized safety studies are warranted to confirm that ultrahigh doses of lovastatin are safe.

We also demonstrated that an adaptive method of dose escalation that has been used extensively in cancer treatment trials may be of use in early-phase stroke trials. The rationale for such a method is that in a serious disease like stroke, with a high likelihood of disability, targeting a dose that is associated with a toxicity of $10 \%$ in order to achieve a benefit in a reduction of the disability is a reasonable approach. Traditional methods, on the other hand, would have targeted levels of toxicity below a given level rather than at that level. The notion of a desired trade-off between toxicity and benefit is common in cancer research, but has been relatively underemphasized in studies on stroke. While there are important differences between cancer trials and stroke trials, including the longer duration and multiple cycles of therapy in oncologic trials, we would suggest that even in stroke trials toxicity may in some cases be used as a marker of efficacy. Medications that reduce neuronal activity and thus reduce the level of alertness, for example, may be of benefit as neuroprotectants even though they are interpreted as showing toxicity. Similar methods have been recommended for use in amyotrophic lateral sclerosis trials 
[38]. In addition, our design permitted greater flexibility in the dose adjustment compared to traditional designs for dose escalation by allowing dose re-escalation after the occurrence of adverse events. It also minimized the likelihood that any patient received a toxic dose of medication.

The study design is particularly efficient at finding the maximal tolerated dose with a limited sample size. Although the $95 \%$ CI for the toxicity rate at the identified MTD is wide, the goal of this study was not to make a definitive safety statement about the MTD. Rather, it was to explore and identify the right dose range. It is of note that the lower limit of the CI at the $10-\mathrm{mg} / \mathrm{kg}$ dose approaches $10 \%$, indicating that this dose would likely exceed the optimal safety range. Further study at $8 \mathrm{mg} / \mathrm{kg}$ is needed to confirm its safety and tolerability, and this study is ongoing.

Our method, the modified time-to-event CRM [33], is even more efficient in allowing staggered patient entry and using toxicity information collected on days $1,2,3$ and 7 . Thus, when new patients arrive before previously treated patients complete their 30-day evaluation, partial information is still available for estimating the dose without suspending the trial and turning away potential subjects. This is particularly important in stroke trials, in which recruitment may be slow and missed opportunities for recruitment are particularly disappointing.

It remains unclear whether the very high doses of statins studied in our trial are able or required to produce clinical neuroprotection in human beings. There is, however, consistent evidence of a benefit of statins when administered to rodent models of acute ischemic stroke, and of a dose-response effect on neuroprotection [6-12, 14]. There is some evidence that higher doses may have less benefit than lower doses when administered at $24 \mathrm{~h}$ after stroke. These data may be interpreted as providing evidence that high-dose therapy must be started early to be effective at reducing infarct size, though it is uncertain when the benefits of the high-dose therapy vanish. Statins may also increase angiogenesis, neurogenesis, and synaptogenesis even when given after an acute neuroprotectant effect is no longer operative [14].

Several recent trials of statins in acute stroke have been performed, with somewhat conflicting results. The largest of these, the Stroke Prevention by Aggressive Reduction in Cholesterol Levels (SPARCL) trial [2], demonstrated the benefit of atorvastatin for secondary stroke prevention when administered to patients without cardiac disease or hyperlipidemia. Importantly, the patients in the trial began their treatment at least 30 days after the stroke, and thus the study cannot be considered a reliable guide to the benefits of statins for acute therapy after stroke. Nor does this study provide any evidence of neuroprotective benefits. Other studies were much smaller. One study [20] was a pilot trial in which patients $(n=60)$ were randomly assigned to simvastatin $40 \mathrm{mg}$ daily or placebo within $12 \mathrm{~h}$ and for 3 days after the stroke, and there was evidence of an improvement in neurological function by 3 days. The functional outcomes did not persist at 3 months and those patients on simvastatin had an increased risk of infections. Interestingly, we also found a high rate (approximately 15\%) of infections in our study, although - because of our nonrandomized design - we could not say whether this effect was dose related, and infections are common complications after stroke. In another trial, the risk of recurrent stroke was not reduced with the use of statin therapy, although the study was stopped early and the number of participants may not have been sufficient to reach a definitive conclusion [23]. Finally, another interesting trial appeared to show that stopping statin therapy in patients already taking statins when admitted with acute stroke can increase the risk of adverse outcomes, including an increased infarct volume and worse functional outcomes. This study was limited by its small sample size $(\mathrm{n}=89$; randomized $)$ and the limited number of participating centers, but does provide indirect evidence of the benefits of statin therapy [21].

The mechanism of potential neuroprotective effects with statins remains uncertain. We found evidence for a dose-related decrease in TNFR1, one of the mediators of the effect of TNF- $\alpha$, though not TNF- $\alpha$ itself. TNFR1 may be a more stable marker than TNF- $\alpha$. TNFR1 is emerging as an important marker of poor outcome after both stroke and myocardial infarction [39], and we have found associations between TNFR1 and mortality in the northern Manhattan population (unpublished data). Recent animal studies have shown that TNFR1 may be associated with decreased neuronal proliferation after stroke, and that abrogation of this activity may enhance recovery [40]. Other studies have demonstrated that TNFR2 is also associated with the neuroprotective effects of lovastatin, but we did not measure TNFR2 levels. We did not find any effects of lovastatin on hsCRP or IL-6 within the 30 days of this study. Future studies will be needed to confirm these findings and to explore for statin effects mediated by endothelial nitric oxide synthase on the cerebral blood flow.

No dramatic effects on lipid parameters were seen within the short time period of high-dose therapy. Importantly, we also did not find any evidence that high- 
dose statin therapy led to either a decrease in the efficacy of aspirin therapy or to any platelet dysfunction. No patients received thrombolytic therapy and further in-vitro studies of interactions of high-dose statin therapy with thrombolytic therapy are warranted, to be followed by studies in patients receiving thrombolytic therapy.

There are limitations to our trial. Because statins are in general poorly soluble, there are no parenteral formulations of statins available for human use. For this reason, we used oral lovastatin, which entailed using a large number of pills. In part, our study provides evidence that oral administration of lovastatin is feasible and associated with linear pharmacokinetics. Importantly, recent animal studies suggest that parenteral formulations of statins are feasible and may have greater neuroprotective effects $[41,42]$. We also had a limited ability to test the mechanism of action of statin therapy as a potential neuroprotectant. Although we measured levels of several inflam- matory markers at different time points after their administration and found evidence of some change in TNFR1 levels, we did not have the funding to perform MRI studies to assess any lesion volume or cerebral blood flow. Finally, this study could not provide any information about statin efficacy, but only about its safety, and we could not reliably determine whether high doses were associated with secondary safety outcomes. Further randomized studies will be required to assess its safety as well as its efficacy and potential mechanisms of action.

\section{Acknowledgments}

Supported by the Specialized Program of Translational Research in Acute Stroke (SPOTRIAS; NIH/NINDS P50 NS49060). The authors also acknowledge the helpful comments of Dr. Michael Moskowitz and the safety committee, Thomas J. Bigger, Shunichi Homma, Petra Kaufmann, and Myunghee C. Paik.

\section{References}

1 Ballantyne CM: Current and future aims of lipid-lowering therapy: changing paradigms and lessons from the Heart Protection Study on standards of efficacy and safety. Am J Cardiol 2003;92(suppl):3K-9K.

$\checkmark 2$ Stroke Prevention by Aggressive Reduction in Cholesterol Levels (SPARCL) Investigators: High-dose atorvastatin after stroke or transient ischemic attack. N Engl J Med 2006;355:549-559.

-3 Heart Protection Study Collaborative Group: MRC/BHF Heart Protection Study of cholesterol lowering with simvastatin in 20,536 high-risk individuals: a randomized placebo-controlled trial. Lancet 2002;360:7-22.

4 Weitz-Schmidt G: Statins as anti-inflammatory agents. Trends Pharmacol Sci 2002;23: 482-486.

5 Chan KKW, Oza AM, Siu LL: The statins as anticancer agents. Clin Cancer Res 2003;9: 10-19.

-6 Endres M, Laufs U, Huang Z, Nakamura T, Huang P, Moskowitz MA, Liao JK: Stroke protection by 3-hydroxy-3-methylglutaryl (HMG)-CoA reductase inhibitors mediated by endothelial nitric oxide synthase. Proc Natl Acad Sci USA 1998;95:8880-8885.

$\checkmark 7$ Amin-Hanjani S, Stagliano NE, Yamada M, Huang PL, Liao JK, Moskowitz MA: Mevastatin, an HMG-CoA reductase inhibitor, reduces stroke damage and upregulates endothelial nitric oxide synthase in mice. Stroke 2001;32:980-986.
8 Laufs U, Gertz K, Dirnagl U, Böhm M, Nickenig G, Endres M: Rosuvastatin, a new HMG-CoA reductase inhibitor, upregulates endothelial nitric oxide synthase and protects from ischemic stroke in mice. Brain Res 2002;942:23-30.

9 Gertz K, Laufs U, Lindauer U, Nickenig G, Böhm M, Dirnagl U, Endres M: Withdrawal of statin treatment abrogates stroke protection in mice. Stroke 2003;34:551-557.

10 Yemisci M, Ay H, Kocaefe C, Qui J, Topalkara K, Ozgüç M, Kirazli S, Ozcebe O, Moskowitz MA, Dalkara T: Statin potentiates human platelet eNOS activity without enhancing eNOS mRNA and protein levels. Cerebrovasc Dis 2008;26:190-198.

11 Balduini W, De Angelis V, Mazzoni E, Cimino M: Simvastatin protects against long-lasting behavioral and morphological consequences of neonatal hypoxic/ischemic brain injury. Stroke 2001;32:2185-2191.

12 Sironi L, Cimino M, Guerrini U, Calvio AM, Lodetti B, Asdente M, Balduini W, Paoletti R, Tremoli E: Treatment with statins after induction of focal ischemia in rats reduces the extent of brain damage. Arterioscler Thromb Vasc Biol 2003;23:322-327.

13 Elkind MSV: Statins as acute stroke treatment. Int J Stroke 2006;1:224-225.

14 Chen J, Zhang ZG, Li Y, Wang Y, Wang L, Jiang H, Zhang C, Lu M, Katakowski M, Feldkamp CS, Chopp M: Statins induce angiogenesis, neurogenesis, and synaptogenesis after stroke. Ann Neurol 2003;53:743751.
15 Jonsson N, Asplund K: Does pretreatment with statins improve clinical outcome after stroke? A pilot case-referent study. Stroke 2001;32:1112-1115.

16 Marti-Fabregas J, Gomis M, Arboix A, et al: Favorable outcome of ischemic stroke in patients pretreated with statins. Stroke 2004; 35:1117-1121.

$>17$ Greisenegger S, Mullner M, Tentschert S, Lang W, Lalouschek W: Effect of pretreatment with statins on the severity of acute ischemic cerebrovascular events. J Neurol Sci 2004;221:5-10.

18 Elkind MS, Flint AC, Sciacca RR, Sacco RL: Use of lipid lowering agents prior to onset of ischemic stroke is associated with decreased mortality. Neurology 2005;65:253-258.

19 Moonis M, Kane K, Schwiderski U, Sandage BW, Fisher M: HMG-CoA reductase inhibitors improve acute ischemic stroke outcome. Stroke 2005;36:1298-1300

20 Montaner J, Chacón P, Krupinski J, Rubio F, Millán M, Molina CA, Hereu P, Quintana M, Alvarez-Sabín J: Simvastatin in the acute phase of ischemic stroke: a safety and efficacy pilot trial. Eur J Neurol 2008;15:82-90.

-21 Blanco M, Nombela F, Castellanos M, Rodriguez-Yáñez M, García-Gil M, Leira R, Lizasoain I, Serena J, Vivancos J, Moro MA, Dávalos A, Castillo J: Statin treatment withdrawal in ischemic stroke: a controlled randomized study. Neurology 2007;69:904910. 
-22 Bushnell CD, Griffin J, Newby LK, Goldstein LB, Mahaffey KW, Graffagnino CA, Harrington RA, White HD, Simes RJ, Califf RM, Topol EJ, Easton JD: Statin use and sex-specific stroke outcomes in patients with vascular disease. Stroke 2006;37:1427-1431.

-23 Kennedy J, Hill MD, Ryckborst KJ, Eliasziw M, Demchuk AM, Buchan AM, FASTER Investigators: Fast assessment of stroke and transient ischaemic attack to prevent early recurrence (FASTER): a randomised controlled pilot trial. Lancet Neurol 2007;6:961969.

-24 Thibault A, Samid D, Tompkins AC, Figg WD, Cooper MR, Hohl RJ, Trepel J, Liang B, Patronas N, Venzon DJ, Reed E, Myers CE: Phase I study of lovastatin, an inhibitor of the mevalonate pathway, in patients with cancer. Clin Cancer Res 1996;2:483-491.

25 Larner J, Jane J, Laws E, Packer R, Myers C, Shaffrey M: A phase I-II trial for anaplastic astrocytoma and glioblastoma multiforme. Am J Clin Oncol 1998;21:579-583.

26 Kim WS, Kim MM, Choi HJ, Yoon S, Lee MH, Park K, Park CH, Kang WK: Phase II study of high-dose lovastatin in patients with advanced gastric adenocarcinoma. Invest New Drugs 2001;19:81-83.

27 Lovastatin Package Insert. Merck \& Co., Inc., 2002.

-28 O’Quigley J, Pepe M, Fisher L: Continual reassessment method: a practical design for phase I trials in cancer. Biometrics 1990;46: 33-48.
29 Cheung YK: Coherence principles in dosefinding studies. Biometrika 2005;92:863873.

30 Elkind MS, Sacco RL, MacArthur RB, Fink DJ, Peerschke E, Andrews H, Neils G, Stillman J, Corporan T, Leifer D, Cheung K: The Neuroprotection with Statin Therapy for Acute Recovery Trial (NeuSTART): an adaptive design phase I dose-escalation study of high-dose lovastatin in acute ischemic stroke. Int J Stroke 2008;3:210-218.

-31 Farmer JA, Torre-Amione G: Comparative tolerability of the HMG-CoA reductase inhibitors. Drug Saf 2000;23:197-213.

32 Ballantyne CM, Corsini A, Davidson MH, Holdaas H, Jacobson TA, Leitersdorf E, März W, Reckless JPD, Stein EA: Risk for myopathy with statin therapy in high-risk patients. Arch Intern Med 2003;163:553-564.

33 Cheung YK, Chappell R: Sequential designs for phase I clinical trials with late-onset toxicities. Biometrics 2000;56:1177-1182.

34 Chevret S: The continual reassessment method in cancer phase I clinical trials: a simulation study. Stat Med 1993;12:10931108.

35 Cheung YK, Chappell R: A simple technique to evaluate model sensitivity in the continual reassessment method. Biometrics 2002;58: 671-674.

36 O'Quigley J: Estimating the probability of toxicity at the recommended dose following a phase I clinical trial in cancer. Biometrics 1992;48:853-862.
37 Sun JX, Niecestro R, Philips G, Shen J, Lukacsko P, Friedhoff L: Comparative pharmacokinetics of lovastatin extended-release tablets and lovastatin immediate release tablets in humans. J Clin Pharmacol 2002;42: 198-204.

38 Cheung YK, Gordon PH, Levin B: Selecting promising ALS therapies in clinical trials. Neurology 2006;67:1748-1751.

39 Valgimigli M, Ceconi C, Malagutti P, Merli E, Soukhomovskaia O, Francolini G, Cicchitelli G, Olivares A, Parrinello G, Percoco G, Guardigli G, Mele D, Pirani R, Ferrari R: Tumor necrosis factor-alpha receptor 1 is a major predictor of mortality and new-onset heart failure in patients with acute myocardial infarction: the Cytokine-Activation and Long-Term Prognosis in Myocardial Infarction (C-ALPHA) study. Circulation 2005; 111:863-870.

40 Iosif RE, Ahlenius H, Ekdahl CT, Darsalia V, Thored P, Jovinge S, Kokaia Z, Lindvall O: Suppression of stroke-induced progenitor proliferation in adult subventricular zone by tumor necrosis factor receptor 1 . J Cereb Blood Flow Metab 2008;28:1574-1587.

41 Prinz V, Laufs U, Gertz K, Kronenberg G, Balkaya M, Leithner C, Lindauer U, Endres $\mathrm{M}$ : Intravenous rosuvastatin for acute stroke treatment: an animal study. Stroke 2008;39: 433-438.

42 Endres M, Laufs U: The medical case for the development of an intravenous statin formulation - beyond ischemic stroke. Cerebrovasc $\mathrm{Dis} 2008 ; 25: 593-594$. 